\title{
Commentary: Perhaps smaller is better in smaller patients
}

\author{
Ibrahim Abdullah, MD, Zohair Al-Halees, MD, and Mamdouh Al Ahmadi, MD
}

\author{
From the Department of Pediatric Cardiac Surgery, King Faisal Specialist Hospital \& Research Center, Riyadh, \\ Saudi Arabia. \\ Disclosures: Authors have nothing to disclose with regard to commercial support. \\ Received for publication Sept 16, 2019; revisions received Sept 16, 2019; accepted for publication Sept 16, 2019. \\ Address for reprints: Ibrahim Abdullah, MD, Department of Pediatric Cardiac Surgery, King Faisal Specialist \\ Hospital \& Research Center, Riyadh, Saudi Arabia (E-mail: iabdullah1234@gmail.com). \\ J Thorac Cardiovasc Surg 2019;158:e193-4 \\ $0022-5223 / \$ 36.00$ \\ Copyright (c) 2019 by The American Association for Thoracic Surgery \\ https://doi.org/10.1016/j.jtcvs.2019.09.032
}

In this issue of the Journal, Saitto and colleagues ${ }^{1}$ describe a case report of a pediatric patient who as a neonate underwent a coarctation repair followed by a partial atrioventricular septal defect repair, which included a cleft closure of a hypoplastic left atrioventricular valve at the age of 3 years. During the latter procedure, a left lateral wall hematoma with associated ST-segment changes was noticed, necessitating extracorporeal membrane oxygenation support. Although she was discharged from this admission, at the age of 9 years, the patient underwent a mechanical mitral valve replacement and surgical ventricular restoration (SVR) for significant heart failure in the setting of a postischemic dilated left ventricle and severe left atrioventricular valve regurgitation and moderate stenosis. She represents the first reported pediatric patient who has undergone a successful recovery of function after SVR.

Although the benefits of partial left ventricular reduction in non-ischemic dilated cardiomyopathy remain questionable, as evidenced by several centers including the Cleveland Clinic in the mid-1990s, ${ }^{2}$ a more contemporary trial sought to answer the question of SVR for ischemic dilated cardiomyopathy. As part of hypothesis 2 of the multicenter STITCH (Surgical Treatment for Ischemic Heart Failure) trial, investigators enrolled a total of 1000 adult patients with an ejection fraction of $35 \%$ or less, coronary artery disease that was amenable to coronary artery bypass grafting $(\mathrm{CABG})$, and dominant left ventricular dysfunction amenable to SVR. ${ }^{3}$ Half of these patients were randomly assigned to a CABG only procedure and half were randomly assigned to CABG with SVR. Interestingly, although the CABG with SVR group experienced a $19 \%$ reduction in end-systolic volume index compared with a $6 \%$ reduction in the CABG-only group, there were no significant differences in the primary outcome of death nor degree of symptom improvement. As such, even in dilated ischemic cardiomyopathy, the benefit of SVR added to CABG remains questionable. However, with their current case report, Saitto and colleagues have

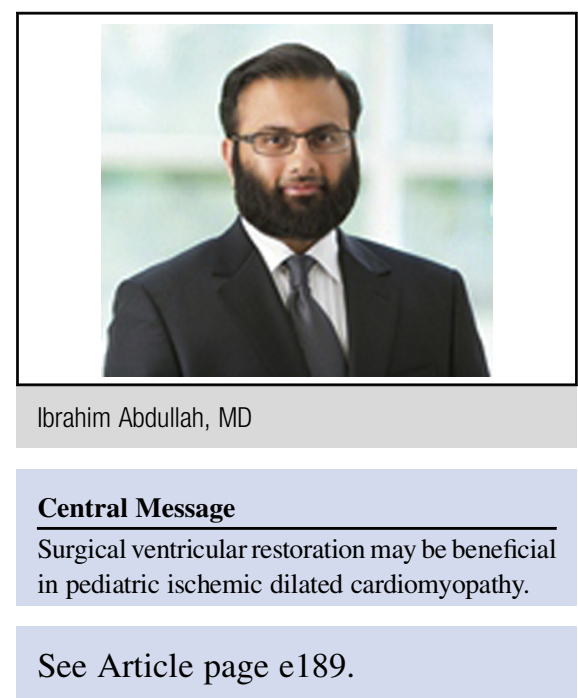

rejuvenated this question for the rare but existing pediatric population with dilated ischemic cardiomyopathy.

Dilated ischemic cardiomyopathy is exceedingly rare in the pediatric population and more often than not associated with an uncorrected iatrogenic coronary injury during a procedure for some other congenital disease. At the King Faisal Specialist Hospital \& Research Center in Riyadh, we recall very few iatrogenic ischemic injuries after pediatric mitral valve replacement over the last 15 years. We recall 2 who underwent coronary stenting. For those who survived, none underwent transplant or SVR. It is indeed quite remarkable that the patient the authors present had a normal coronary catheterization almost 3 years after the initial ischemic injury. In essence, she had theoretically already benefited from a natural revascularization. However, despite that, she remained significantly symptomatic, with ventricular arrhythmias that only improved after SVR. Although we may never achieve a randomized controlled trial of SVR in dilated ischemic cardiomyopathy of the pediatric population, this sentinel report will hopefully encourage more reports of experiences in this rare but often complex situation.

\section{References}

1. Saitto G, Castelvecchio S, Arcidiacono C, Menicanti L. Surgical ventricular restoration and mitral valve replacement in a pediatric patient with complex congenital heart disease and malignant ventricular arrhythmias. J Thoracic Cardiovasc Surg. 2019;158:e189-91. 
2. Franco-Cereceda A, McCarthy PM, Blackstone EH, Hoercher KJ, White JA, Young JB, et al. Partial left ventriculectomy for dilated cardiomyopathy: is this an alternative to transplantation? J Thoracic Cardiovasc Surg. 2001;121:879-93.
3. Jones RH, Velazquez EJ, Michler RE, Sopko G, Oh JK, O'Connor CM, et al. Coronary bypass surgery with or without surgical ventricular reconstruction. $N$ Engl J Med. 2009;360:1705-17. 